\title{
DIVULGACIÓN \\ MICROORGANISMOS EFICIENTES Y SU BENEFICIO PARA LA AGRICULTURA Y EL MEDIO AMBIENTE
}

\author{
Arnol Arias Hoyos ${ }^{1}$ \\ ${ }_{1}$ Grupo de investigación en energía alternativas y microorganismos eficientes, Corporación \\ Universitaria autónoma del Cauca, Popayán, Colombia
}

Recibido: 30 de Mayo de 2010; Revisado: 16 de Junio de 2010; Aceptado: 9 de Julio de 2010

\begin{abstract}
El uso de microorganismos eficientes EM en el sector agrícola, aplicándolo en el manejo de instalaciones, alimentación, manejo de excretas y manejo de praderas ha permitido darle al suelo una buena utilización y por consiguiente su recuperación, lo que al mismo tiempo permite obtener buenos resultados en el saneamiento ambiental, esto se debe a que la aplicación de dichos microorganismos sobre los residuos sólidos orgánicos pueden generar compost y en el componente hídrico es útil para manejo de las Ptars (planta de tratamiento de aguas residuales) lo cual reducirá la carga contaminante. Por lo tanto la aplicación de esta tecnología actualmente esta beneficiando a los agricultores, la sanidad de los animales, los profesionales del manejo ambiental y a toda la comunidad interesada en aprovechar los recursos naturales de forma sostenible y sin contaminar el medio ambiente.
\end{abstract}

Palabras Clave: Microorganismos eficientes, bacterias fototróficas, bacterias acido lácticas, levaduras, Ptar's, Pgir's, compost.

\section{INTRODUCCIÓN}

ctualmente el crecimiento de la población hace que la Ademanda de alimentos sea mayor, por lo que los productores deben buscar la forma de aumentar y acelerar los procesos de producción para poder suplir dicha demanda. El problema a que esto conlleva es de tipo ambiental y agrícola pues se está presentando un acelerado deterioro de los suelos por la presencia de monocultivos y del uso de fertilizantes e insecticidas químicos, esto sin contar el factor económico que afecta directamente el bolsillo del campesino productor por los altos costos de los abonos químicos y al ambiente porque se están convirtiendo suelos fértiles en suelos degradados biológica y económicamente. [1]

Los proyectos relacionados con la tecnología EM, tiene como objetivo contribuir al mejoramiento productivo y ambiental a través de la utilización de microorganismos eficientes y de esta forma contribuir al mejoramiento económico y social de las comunidades rurales

\section{TEORÍA}

Uno de los principales problemas ambientales y del sector agrícola hoy en día es el acelerado deterioro de los suelos debido al continuo crecimiento de los monocultivos y del uso de fertilizantes e insecticidas químicos. La necesidad de suplir la alta demanda de alimentos hace que los productores quieran por cualquier medio (siendo el más usado el de tipo químico) acelerar los procesos de germinación, crecimiento y producción sin importar el perjuicio que se le cause a los suelos y sobre todo a los consumidores finales. Es por esto que surge la necesidad de utilizar para el proceso de germinación mecanismos de tipo biológico que remplacen los métodos químicos hasta ahora usados, esto permitirá mejorar la calidad del alimento lo cual se verá reflejado en la salud del consumidor final, disminuirá el acelerado proceso de contaminación que está presentando el suelo y el rendimiento económico del productor será mayor puesto que el uso de microorganismos eficientes abaratara los costo, comparado con la inversión que se debe hacer con el uso de fertilizantes químicos.

Nadamos en un mar de microorganismos. Existen microorganismos en el aire, agua, suelo, en nuestros intestinos, en los alimentos que consumimos, en el agua que bebemos. Las condiciones actuales de contaminación y uso excesivo de sustancias químicas sintéticas han causado la proliferación de especies de microorganismo considerados degeneradores. Estos microorganismo a grandes rasgos, son causantes de enfermedades en plantas $\mathrm{y}$ animales, generan malos olores y gases nocivos al descomponer residuos orgánicos. [2]

Al aplicar EM a suelos, aguas residuales y desechos orgánicos, la población de microorganismos es 
modificada hacia una que produce sustancias benéficas para la vida animal y vegetal. EM, es una abreviación de (Microorganismos Eficaces), cultivo mixto de microorganismos benéficos naturales, sin manipulación genética, presentes en ecosistemas naturales, fisiológicamente compatibles unos con otros.

Cuando el EM es inoculado en el medio natural, el efecto individual de cada microorganismo es ampliamente magnificado en una manera sinérgica por su acción en comunidad. La tecnología EM, fue desarrollada por Teruo Higa, Ph. D, profesor de horticultura de la universidad de Ryukyus en Okinawa, Japón. A comienzos de los años sesenta, el profesor Higa comenzó la búsqueda de una alternativa que reemplazara los fertilizantes y pesticidas sintéticos, popularizados después de la segunda guerra mundial para la producción de alimentos en el mundo entero. [3]

Los microorganismos efectivos o EM son una cultura mixta de microorganismos benéficos (fundamentalmente bacterias fotosintéticas, productoras de ácido láctico, levaduras, actinomycetes y hongos fermentadores) que pueden aplicarse como inoculante para incrementar la diversidad microbiana de los suelos. Esto a su vez aumenta la calidad y la salud de los suelos, lo que a su vez aumenta el crecimiento, la calidad y el rendimiento de los cultivos.

\section{Modo de Acción de los Microorganismos}

Los diferentes tipos de microorganismos en el EM, toman sustancias generadas por otros organismos basando en ello su funcionamiento y desarrollo. Las raíces de las plantas secretan sustancias que son utilizadas por los Microorganismos Eficaces para crecer, sintetizando aminoácidos, ácidos nucleicos, vitaminas, hormonas y otras sustancias bioactivas. Cuando los Microorganismos Eficaces incrementan su población, como una comunidad en el medio en que se encuentran, se incrementa la actividad de los microorganismos naturales, enriqueciendo la microflora, balanceando los ecosistemas microbiales, suprimiendo microorganismos patógenos. [5]

\section{Bacterias Fototróficas}

Son bacterias autótrofas (Rhodopseudomonas spp) que sintetizan sustancias útiles a partir de secreciones de raíces, materia orgánica y gases dañinos, usando la luz solar y el calor del suelo como fuentes de energía.
Las sustancias sintetizadas comprenden aminoácidos, ácidos nucleicos, sustancias bioactivas y azúcares, promoviendo el crecimiento y desarrollo de las plantas. Los metabolitos son absorbidos directamente por ellas, y actúan como sustrato para incrementar la población de otros Microorganismos Eficaces.

\section{Bacterias Ácido Lácticas}

Estas bacterias (Lactobacillus spp) producen ácido láctico a partir de azúcares y otros carbohidratos sintetizados por bacterias fototróficas y levaduras. El ácido láctico es un fuerte esterilizador, suprime microorganismos patógenos e incrementa la rápida descomposición de materia orgánica. Las bacterias ácido lácticas aumentan la fragmentación de los componentes de la materia orgánica, como la lignina y la celulosa, transformando esos materiales sin causar influencias negativas en el proceso. [4]

\section{Levaduras}

Estos microorganismos (saccharomyces spp) sintetizan sustancias antimicrobiales y útiles para el crecimiento de las plantas a partir de aminoácidos y azúcares secretados por bacterias fototróficas, materia orgánica y raíces de las plantas. [6]

Las sustancias bioactivas, como hormonas y enzimas, producidas por las levaduras, promueven la división celular activa. Sus secreciones son sustratos útiles para Microorganismos Eficaces como bacterias ácido lácticas y actinomycetos. [5]

El concepto de la inoculación de suelos y plantas con microorganismos benéficos para crear un ambiente microbiano más favorable para el crecimiento de las plantas ha sido motivo de discusión durante décadas por parte de los científicos dedicados a la agricultura.

El principio biológico que determina la actuación de este consorcio de bacterias se basa, entre otras propiedades, en su carácter antioxidante. Además, cuando estos microorganismos entran en contacto con la materia orgánica, secretan sustancias benéficas como vitaminas, ácidos orgánicos y minerales. Así mismo, prosperan por exclusión competitiva, tanto en nichos contaminados como en descomposición, para luego morir cuando las condiciones son limpias, por lo cual no existe riesgo de contaminación secundaria. [6] 


\section{Otros usos del E.M}

Los microorganismos en la agricultura, el EM como inoculante microbiano, restablece el equilibrio microbiológico del suelo, mejorando sus condiciones físico-químicas, incrementa la producción de los cultivos y su protección, además conserva los recursos naturales, generando una agricultura y medio ambiente más sostenible.

Los E.M pueden ser utilizados en la industria animal (porcicultura, ganadería y avicultura) para la cría de animales, el incremento de las variables productivas, maximizando la eficiencia de los sistemas y en el manejo de excretas e instalaciones. [7]

Son una buena alternativa dentro del saneamiento ambiental, la utilización de microorganismos como herramienta biológica permiten transformar desechos para ser usados como nutrientes; pudiéndose aplicar en el tratamiento de aguas residuales domesticas e industriales y en residuos sólidos con lo cual se pueden producir fertilizantes y evitar la proliferación de insectos vectores. [8]

\section{Efectos del EM}

a. Los siguientes son algunos de los efectos benéficos de la aplicación del EM

b. Promueve la germinación, la floración, el desarrollo de los frutos y la reproducción de las plantas.

c. Mejora física, química y biológicamente el ambiente de los suelos, y suprime los patógenos y pestes que promueven enfermedades

d. Aumenta la capacidad fotosintética de los cultivos.

e. Asegura una mejor germinación y desarrollo de las plantas.

f. Incrementa la eficacia de la materia orgánica como fertilizante

g. Reducción de malos olores y por lo tanto reducción en la utilización de desinfectantes

h. Disminuye el consumo de agua de lavado, implementando el manejo de camas secas para colectar excretas

i. Ayuda al aprovechamiento eficiente de desechos animales j. Mejora la calidad y aumenta la rapidez en la elaboración del abono.

k. Reincorpora aguas residuales como aguas de riego.

1. Mejora la calidad de los productos animales.

m. Promueve la transformación aeróbica de compuestos orgánicos, evitando la descomposición de la materia orgánica por oxidación en la que se generan gases sulfurosos $\mathrm{y}$ amoniacales.

n. Reduce valores de DBO y DQO

o. Reduce la producción de lodos en sistemas de tratamientos convencionales.

\section{CONCLUSIONES}

Los microorganismos eficientes, al ser un producto orgánico sin manipulación genética son bien aceptados en toda clase de unidades productivas, ya sean agrícolas, pecuarias o ambientales.

El uso de EM requiere de menores cantidades de materia orgánica ahorrando costos de aplicación de esta al suelo.

Con la aplicación de la tecnología EM se hace posible la transformación de los residuos orgánicos en abonos de excelente calidad utilizados en programas de producción limpia.

La aspersión de microorganismos eficientes en las instalaciones en donde se encuentran las excretas de los cerdos y el ganado reduce drásticamente los gases emitidos producto de los malos olores y la presencia de vectores.

La tecnología EM, aplicada en el tratamiento de aguas residuales (Ptar's, Pgirs) permite recuperar este tipo de aguas lo que minimiza diferentes impactos generados al medio ambiente e incluso darle un nuevo uso.

El uso de agroquímicos además de ser de alto costo en la mayoría de los países, hacen que el suelo pierda diversidad de flora y fauna y que se destruya su materia orgánica, mientras que el EM mejora la biota del suelo, las propiedades físicas de esté, disminuyendo los costos de la producción, aumentado la cantidad de cosechas y por lo tanto aumentado los ingresos del agricultor.

En el agua potable: Remueve la materia orgánica; optimiza procesos unitarios en las plantas de tratamiento; 
reduce la producción de compuestos organoclorados en sistemas convencionales y racionaliza el uso de agentes químicos. En el agua residual: Transforma la materia orgánica disminuyendo la producción de lodos; mejora la calidad física, química y microbiológica del efluente de una planta de tratamiento de aguas residuales (PTAR) e inhibe la producción de olores ofensivos. En residuos sólidos: En procesos de compostaje, acelera la transformación de la materia orgánica y elimina olores molestos en botaderos, rellenos sanitarios, estaciones de manejo de residuos y en carros recolectores.

Los desechos agrícolas, la descarga de aguas contaminadas y la emisión de dioxina que se desarrolla por la incineración y la desintegración de materia orgánica, son algunos de los problemas que se pueden enfrentar de manera exitosa con la aplicación de la tecnología del EM

\section{REFERENCIAS}

[1]

Microorganismos

eficaces.

http://aia.uniandes.edu.co/Documentos/ARTICULO $\% 20$

EM\%20_Manuel\%20R..pdf

[2] Microorganismos eficientes - SCD-EM. http://www.grupoprotech.net/scd\%20em.html

[3] Castellanos Yino Alexander. Tres bacterias para el nuevo siglo. UN periódico - Bogotá Cundinamarca, Marzo 2004. http://biodiversityreporting.org/article.sub?docId=13400 $\& c=$ Colombia $\&$ cRef $=$ Colombia $\&$ year $=2005 \&$ date $=$ Marc $\mathrm{h} \% 202004$

[4]. Higa Terou and Parr James F. "microorganismos en los suelos" departamento de agricultura de los EE.UU. Beltsville. Maryland, EE.UU. http://www.iespana.es/em/Manuales/manuales.html

[5]. Fundases, EMRO Microorganismos Eficientes: http://www.fundases.org

[6]. Mecanismos del EM en el tratamiento de aguas. http://www.iespana.es/em/Manuales/manuales.html

[7]. Manual de reciclado de residuos domésticos con microorganismo eficientes. http://www.iespana.es/em/Manuales/manuales.html
[8]. Hoyos H. Deiver, Alvis G. Nelson y otros. Utilidad de los microorganismos eficientes EM en una explotación avícola. http://www.ecotecnologias.com.ve/

Arnol Arias Hoyos: Biólogo de la Universidad del Cauca, 10 años de Docencia Universitaria en las instituciones: Corporación Universitaria Autónoma del Cauca y la Fundación Universitaria de Popayán, en los programas de Ecología, Ingeniería Industrial, Ingeniería ambiental y en el técnico en producción bovina en las áreas de Biología, Genética, Química, Microbiología, Contaminación ambiental, Evaluación de Impacto ambiental. Coordinador de laboratorios de la Fundación Universitaria de Popayán. Área de investigación en microorganismo eficientes y estudio en calidad físico química y biológica de aguas. 